\title{
RELIABILITY OF EC 155 B1 AIRCRAFT COMPONENTS USING UPPER CONTROL LIMIT (ALERT LEVEL) FORMULATION
}

\author{
Ali Mahroni \\ Jurusan Teknik Dirgantara-Sekolah Tinggi Teknologi Adisutjipto \\ alimahroni123@gmail.com
}

\begin{abstract}
Airport Rescue \& Fire Fighting equipment at Adi Soemarmo International Airport, Operational Vehicle PKP-PK, the number of main vehicles is 3 units, and 6 supporting units meet the standard requirements that have been determined according to the PKP-PK category at Adi Soemarmo Airport, namely category 8. it has a Daily Checklist of operational equipment in each main vehicle and support vehicle. Supporting Facilities for Airport Rescue \& Fire Fighting totaled 194 where required for category 8 was 167 but there were still some shortcomings of the equipment needed. This can be shown in the table, namely the types of hydraulic / electrical (or combination) portable rescue equipment, oxygen resuscitation, and thermal imaging cameras. There are 380 Supporting Reserve Facilities for Rescue \& Fire Fighting where the minimum equipment required is 355 but there is a lack of equipment, namely Proximity suit, Resuscitator, Helmet, and Binocular equipment.
\end{abstract}

Keyword : Fire Fighting, PKP-PK, ATA Facilities and Airport

\section{Latar Belakang}

Bandar Udara Internasional Adi Soemarmo Surakarta dikelola oleh instansi yang telah diberi wewenang oleh pemerintah, dan instasi pemerintah yang terkait antara lain Departemen Perhubungan, PT. Angkasa Pura I (Persero), dan PT. Angkasa Pura II (Persero). Untuk Bandar Udara Internasional Adi Soemarmo Surakarta sendiri dikelola oleh instansi PT. Angkasa Pura I (Persero) dengan melaksanakan tugas maupun fungsi bandar udara, pihak pengelola bandar udara membentuk Divisi, Dinas, maupun Unit Pelayanan untuk mengelola sebuah bandar udara. Adapun Divisi penunjang tugas dan fungsi bandar udara, salah satunya adalah unit Pertolongan Kecelakaan Penerbangan dan Pemadam Kebakaran (PKP-PK). Dalam memberikan pelayanan tersebut unit PKP-PK mempunyai tugas memberikan pertolongan terhadap kecelakaan penerbangan, khususnya kecelakaan pesawat udara yang terjadi di darat. Setiap kecelakaan penerbangan baik dalam keadaan terbakar maupun tidak terbakar akan menimbulkan kerugian. Pelaksanaan operasi PKP-PK adalah berusaha untuk memberikan pertolongan dengan maksud mencegah dan mengurangi kerugian-kerugian khususnya korban jiwa manusia [1][2]. Saat operasi pemadaman adalah saat krusial yang membutuhkan pengerjaan yang efektif dan efisien sehingga usaha terhadap pertolongan korban dapat berjalan lancar. Penempatan kendaraan yang cepat, pertimbangan matang dan siasat yang tepat untuk melakukan operasi pemadaman. Dengan adanya fasilitas pelayanan terhadap keadaaan darurat yang lengkap, maka pembelajaran dan pelatihan terhadap personel untuk mengikuti perkembangan teknologi yang diterapkan dalam fasilitas tersebut adalah menjadi sebuah kewajiban. Serta kegiatan penanggulangan keadaan darurat apabila terjadi kecelakaan didaerah landasan pacu dan sekitarnya [2][4].

\section{Metodologi Penelitian}

Penelitian ini merupakan penelitian deskriptif kualitatif. Penelitian deskriptif merupakan suatu penelitian yang bertujuan melukiskan secara sistematis fakta atau karakteristik tertentu atau bidang tertentu secara faktual dan cermat. Sedangkan kualitatif adalah suatu cara penelitian yang menghasilkan data deskriptif analisis yaitu apa yang dinyatakan atau diinformasikan oleh responden secara tertulis atau lisan dan juga perilakunya secara nyata, 
yang diteliti dan dipelajari sebagai suatu yang utuh, dalam arti penelitian yang memberikan gambaran yang benar mengenai obyek permasalahan.

Untuk mendapatkan data yang dibutuhkan dalam penyusunan Tugas Akhir ini penulis menggunakan Metode pengumpulan data sebagai berikut:

a. Metode observasi

Observasi adalah Metode pengumpulan data yang digunakan untuk menghimpun penelitian melalui pengamatan langsung dilapangan terhadap permasalahan yang diambil.

b. Studi pustaka

Studi pustaka adalah cara untuk mendapatkan informasi dan data dari buku-buku yang dijadikan referensi penelitian dan juga catatan perkuliahan untuk melengkapi informasi yang dibutuhkan dalam permasalahan.

Diagram alir penelitian Analisis Kesiapan PKP-PK Bandar Udara Internasional Adi Soemarmo Surakarta sebagai berikut :

a. Studi pendahuluan

Pada studi pendahuluan ini membahas tentang keadaan pra penelitian, dimana dalam studi pendahuluan ini akan mencari pokok permasalahan yang akan diteliti. Pokok permasalahan dalam pendahuluan ini didapat dari bimbingan ataupun wawancara terhadap dosen/ orang yang berkompeten dalam pokok permasalahan yang diangkat, ataupun mencari referensi objek yang akan diteliti baik itu melalui internet ataupun bukubuku bahkan skripsi-skripsi mahasiswa yang telah lulus yang ada di perpustakaan.

b. Rumusan masalah, tujuan penelitian, batasan masalah

Pada alir ini membahas tentang apa saja masalah yang akan dibahas dalam penyusunan skripsi ini, dan tujuan apa yang hendak dicapai dalam penelitian ini, begitupun akan ada batasan masalah dalam pembahasan skripsi ini, agar pembahasan terarah dan terfokus agar tidak melebar kemana-mana yang bukan dalam batasan permasalahan ini.

c. Tinjauan pustaka

Tinjauan pustaka merupakan landasan teori yang akan menjadi referensi penyusunan skripsi ini. Baik itu teori penyusunan laporan, ataupun teori penelitian permasalahan yang akan diteliti sesuai dengan pokok permasalahan yang telah diambil. Referensi-referensi itu didapat dari buku-buku bahkan jurnal yang ada hubungannya dengan pokok permasalahan, sehingga penulis mendapat pandangan terhadap arah penyusunan dan pengolahan data yang didapat dalam penelitian.

d. Pengambilan data

1) Langkah pertama

Mengetahui data spesifikasi dan jumlah perlengkapan PKP-PK yang digunakan dalam operasi penerbangan.

2) Langkah kedua

Mengetahui Standar kelengkapan peralatan PKP-PK yang ada di Bandar Udara Adi Soemarmo sesuai dengan standar peraturan yang dikeluarkan Departemen Perhubungan Direktur Jendral Perhubungan Udara Nomor KP.14 tahun 2015, dan sebagai perbandingan untuk menentukan kategori terhadap hasil penelitian.

3) Langkah ketiga

Mengetahui data yang diperoleh dari obyek penelitian dilapangan secara langsung dan diperoleh dari sumber-smber lain seperti buku refernsi, studi pustaka, jurnal, serta sumber lain yang berhubungan dengan topik penelitian.

e. Penentuan dalam tahap ini, terdiri dari:

1) Kelengkapan Peralatan serta Jumlah dan kualifikasi personel dari unit PKP-PK di Bandar Udara Adi Soemarmo. 
2) Tingkat kesiapan dan level minimum Kategori PKP-PK di Bandar Udara Adi Soemarmo.

3) Upaya peningkatan Airport Rescue \& Fire Fighting Bandar Udara Internasional Adi Soemarmo Surakarta dilihat dari hasil uji Simulasi Response Time PKP-PK tiap bulan jika terjadi accident di area airside.

f. Analisa dan Pembahasan

Pembahasan merupakan isi dari pemahaman terhadap permasalahan yang diambil dan hasil analisa yang diperoleh dari analisis setelah penelitian. Dalam tahap ini dilakukan pemenuhan standar teknis dan kategori PKP-PK berdasarkan pada Peraturan Direktur Jenderal Perhubungan Udara Nomor KP.14 Tahun 2015.

g. Kesimpulan dan Saran

Kesimpulan dan saran merupakan tahap akhir penyusunan skripsi ini, dimana pada bagian ini didapat jawaban dari tujuan yang hendak dicapai dari permasalahan yang diambil. Begitupun adanya saran-saran terhadap hasil analisis dari penelitian yang dapat membangun dan kelancaran penelitian berikutnya.

\section{Hasil dan Pembahasan}

Pada Peraturan Direktur Jendral Perhubungan Udara No. KP 14 Tahun 2015 untuk jumlah kendaraan utama dan kendaraan pendukung yang dipersyaratkan harus sesuai. Berikut dibawah ini sebagai contoh gambar kendaraan operasional PKP-PK dan kebutuhan jumlah kendaraan utama maupun kendaraan pendukung PKP-PK di bandar Udara Adi Soemarmo Surakarta pada tabel 1.

Tabel 1. Kendaraan Operasional PKP-PK Kendaraan Operasional PKP-PK Bandar Udara Adi Soemarmo Surakarta

\begin{tabular}{|l|l|c|c|}
\hline No & \multicolumn{1}{|c|}{ Nama Kendaraan } & Jumlah & Gambar Kendaraan \\
\hline 1 & $\begin{array}{l}\text { Commando Car } \\
\text { (Mobil Komando) }\end{array}$ & & \\
\hline 2 & Foam Tender Type 1 & & \\
\hline
\end{tabular}




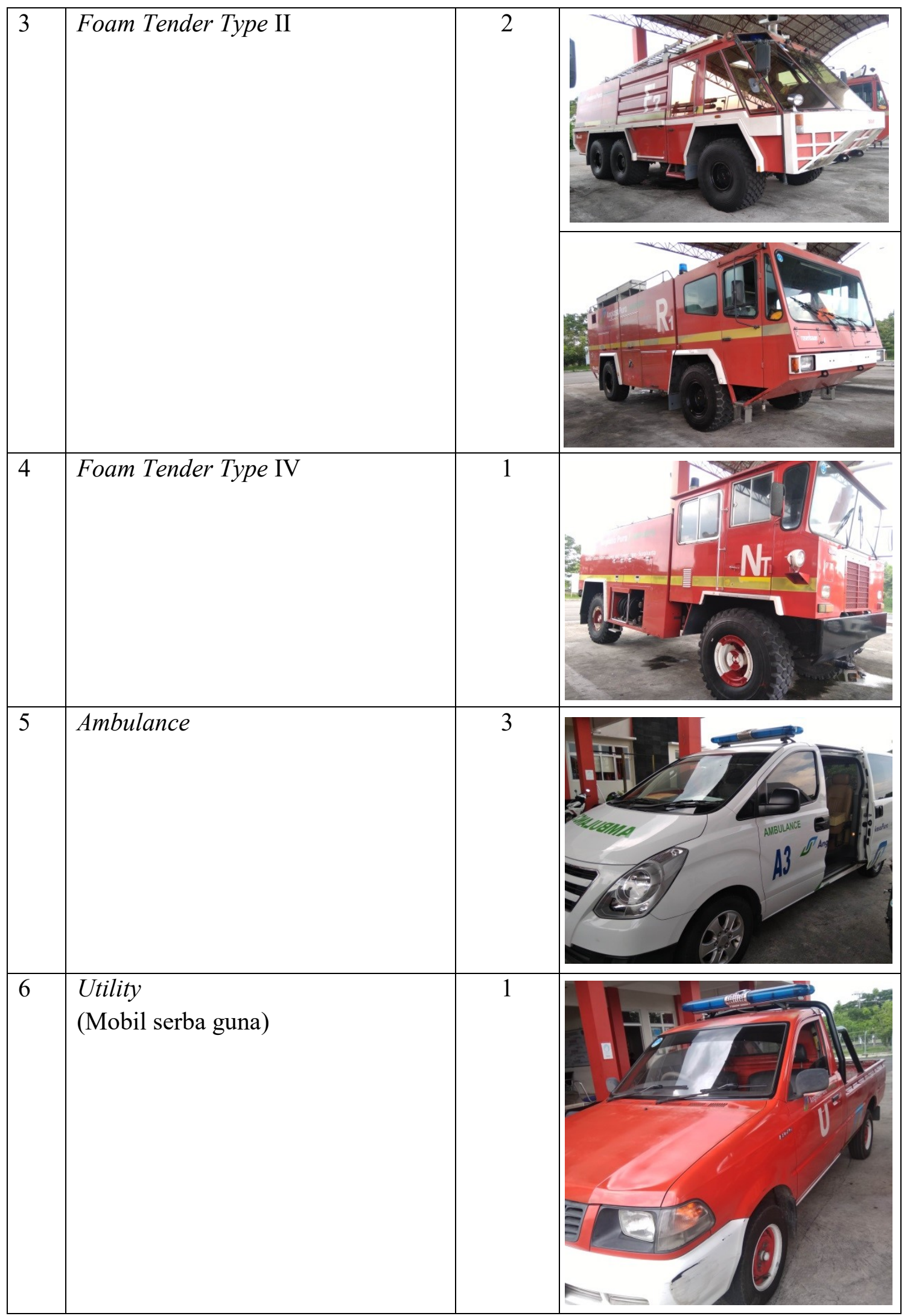


Setiap Kendaraan Utama dan Kendaraan pendukung mempunyai fungsi kendaraan masing-masing, antara lain:

a. Commando Car (Mobil Komando)

Kendaraan Komando (Commando Car) adalah kendaraan pendukung dalam pelayanan PKP-PK yang dirancang khusus sebagai pemandu operasional kendaraan PKP-PK. Dalam operasi pemadaman yanng dilakukan unit PKP-PK, kegunaannya sebagai pengatur jalannya operasi pertolongan atau pemadaman, yang dikendarai oleh komandan operasi (Commander). Kendaraan ini memiliki ukuran lebih kecil dibanding kendaraan Foam Tender namun mampu bergerak di segala medan (on the road and off the road) karena dilengkapi dengan penggerak (axle) di tiap rodanya, atau disebut four wheel drive (4WD). Kendaraan ini mampu berakselerasi cepat dan mampu dipacu dalam kecepatan tinggi, karena menggunakan mesin dengan kapasitas cukup besar. Ground clearance yang tinggi, dengan tapak roda yang lebar, mempermudah pengendalian kendaraan ini pada medan-medan yang berat.

b. Foam Tender Type 1

Foam Tender Type I atau disebut dengan Oshkosh F1 memiliki kapasitas tangki air dengan besar ukuran 11.600 liter, tangki foam konsentrat 1.500 Liter, dan tangki tepung kimia kering (dry chemical powder) $225 \mathrm{~kg}$, kapasitas pompa minimum 6.000 liter per menit dan kapasitas pancaran utama busa minimum 5.000 liter permenit; dilengkapi dengan bumper turret, handlines, nozzle di bawah dan di depan kendaraan, monitor, akselerasi 0 sd $80 \mathrm{~km} / \mathrm{jam}$ dalam 40 detik, kecepatan minimum $100 \mathrm{~km} / \mathrm{jam}$, jarak pancaran rata-rata (discharge range) minimum 70 meter, jarak pengereman (stop distance) maksimum 12 meter pada kecepatan $32 \mathrm{~km} / \mathrm{jam}$. Kemampuannya dapat menangani pesawat terbesar yang dilayani di Bandara Adi Soemarmo seperti Airbus 330, Boeing 747, dan Boeing 777.

c. Foam Tender Type II

Kapasitas tangki air 9.000 liter, tangki foam konsentrat 1.200 Liter, kapasitas pompa minimum 5.500 liter per menit dan kapasitas pancaran utama busa minimum 4.500 liter per menit; dilengkapi dengan bumper turret, handlines, nozzle di bawah dan di depan kendaraan, monitor; akselerasi 0 sd $80 \mathrm{~km} / \mathrm{jam}$ dalam 40 detik pada kondisi jalan rata dan jarak pandang baik, kecepatan minimum $100 \mathrm{~km} / \mathrm{jam}$, jarak pancaran rata-rata (discharge range) minimum 70 meter, jarak pengereman (stop distance) maksimum 12 meter pada kecepatan $32 \mathrm{~km} / \mathrm{jam}$. Kemampuannya dapat menangani pesawat Wide Body yang dilayani di Bandara Adi Soemarmo Surakarta.

d. Foam Tender Type II

Foam Tender Type II atau disebut dengan Rosenbauer R1 memiliki kapasitas tangki air 4.500 liter, foam konsentrat 550 Liter, dan tangki tepung kimia kering (dry chemical powder) $500 \mathrm{~kg}$, kapasitas pompa minimum 5.500 liter per menit dan kapasitas pancaran utama busa minimum 4.500 liter per menit; dilengkapi dengan bumper turret, handlines, nozzle di bawah dan di depan kendaraan, monitor; akselerasi $0 \mathrm{sd} 80 \mathrm{~km} / \mathrm{jam}$ dalam 40 detik pada kondisi jalan rata dan jarak pandang baik, kecepatan minimum $100 \mathrm{~km} / \mathrm{jam}$, jarak pancaran rata-rata (discharge range) minimum 70 meter, jarak pengereman (stop distance) maksimum 12 meter pada kecepatan $32 \mathrm{~km} / \mathrm{jam}$. Kemampuan dari Foam Tender Type II ini dapat menangani pesawat Wide Body yang dilayani di Bandara Adi Soemarmo Surakarta.

e. Ambulance

Kendaraan ini dirancang khusus untuk mengangkut dan memindahkan korban akibat dari kecelakaan penerbangan ataupun kecelakaan di sekitar Bandara Internasional Adi Soemarmo Surakarta dan memiliki peralatan P3K yang lengkap. 
f. Utility Car (Mobil Serba Guna)

Utility Car atau Mobil Serba Guna adalah kendaraan yang berfungsi untuk mendukung operasional PKP-PK, menyalurkan peralatan pendukung dan kegiatan Operasional PKPPK.

Jumlah Personel PKP-PK di Bandar Udara Adi Soemarmo dan Jumlah Teknik Pemeliharaan pada bagian dibawah ini diharapkan terpenuhi sesuai dengan standar Peraturan Direktur Jendral Perhubungan Udara No. KP 14 Tahun 2015, agar tugas operasional Unit PKPPK berjalan dengan baik. Dengan menggunakan rumus untuk menentukan kebutuhan jumlah personel PKP-PK bandar Udara Adi Soemarmo, didapatkan data personel PKP-PK dengan struktur organisasi pada gambar 4.12 yang merupakan Unit PKP-PK diklasifikasikan dalam tipe A untuk kategori 8 s/d 10.

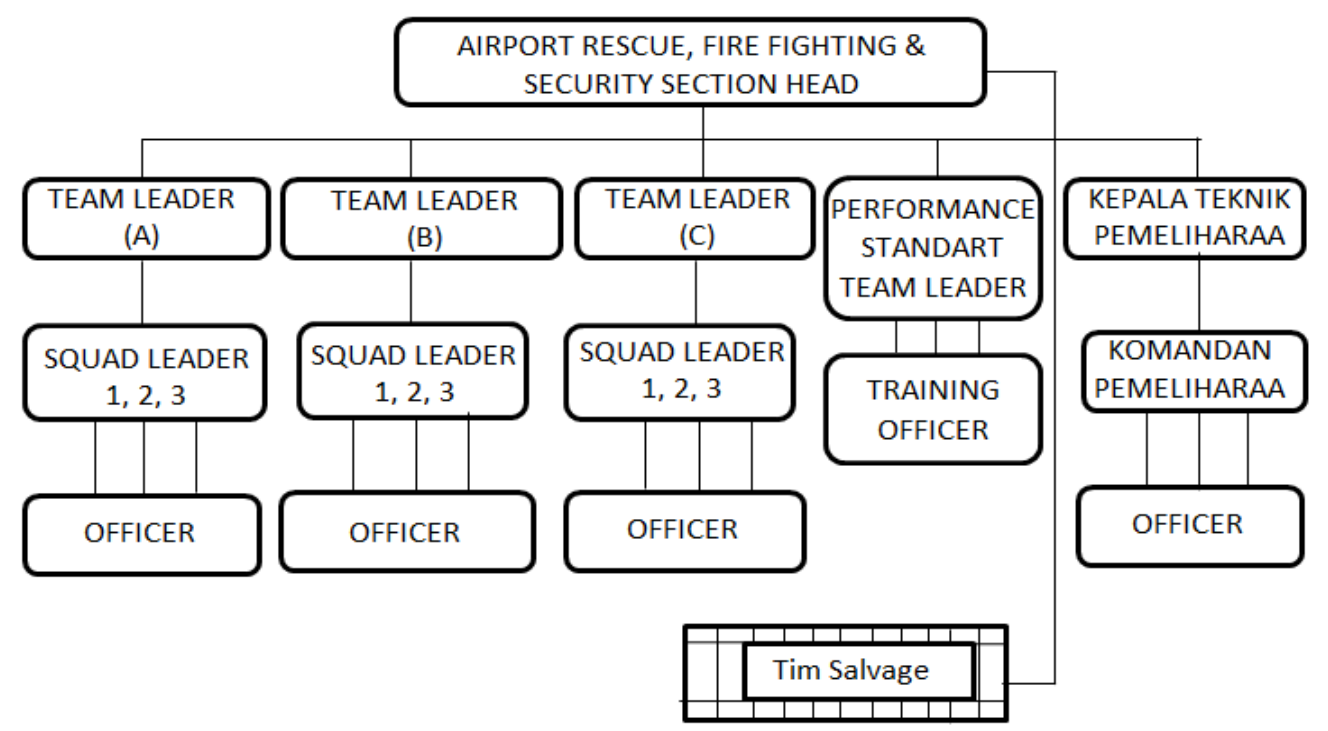

Gambar 1. Bagan Struktur Unit ARFF Sumber: Airport Rescue \& Fire Fighting (ARFF)

Data jumlah minimum personil Airport Rescue \& Fire Fighting bisa diperoleh dari tabel 2

Tabel 2. Perhitungan Jumlah Minimum Personil

\begin{tabular}{|l|l|c|c|}
\hline No & \multicolumn{1}{|c|}{ Kebutuhan } & Keterangan & Jumlah \\
\hline 1 & Jumlah Kendaraan Utama & KU & 3 Unit \\
\hline 2 & Jumlah Kendaraan Pendukung & KP & 6 Unit \\
\hline 3 & Teknisi Pemeliharaan & TP & 3 \\
\hline 4 & Shift Kerja Per Hari & S & 2 \\
\hline
\end{tabular}

Rumus menentukan kebutuhan jumlah personel PKP-PK

$$
\begin{aligned}
\mathrm{JMP} & =((3 \mathrm{KU}+2 \mathrm{KP}) \times \mathrm{S})+\mathrm{TP} \\
& =((3 \times 3+2 \times 6) \times 2)+3 \\
& =45 \text { Personel }
\end{aligned}
$$


Sehingga Kategori-8 untuk bandar Udara Adi Soemarmo Surakarta didapatkan kebutuhan jumlah minimum berjumlah 45 personel dan bisa dilihat dari hasil perhitungan tersebut.Penetapan Kategori Bandar Udara Internasional Adi Soemarmo Surakarta adalah salah satunya mampu didarati pesawat besar seperti jenis Airbuss A330, Boeing 747, dan Boeing 777. Airbuss A330 biasanya dioperasikan untuk penerbangan haji atau beberapa penerbangan ekstra di musim Ramadhan. Dengan kriteria Spesifikasi Pesawat pada tabel 3.

Tabel 3. Spesifikasi Pesawat

\begin{tabular}{|c|l|c|c|c|}
\hline No & Jenis Pesawat & Length & Fuselage Width & Category \\
\hline 1 & A330-300 & $63.66 \mathrm{~m}$ & $5.64 \mathrm{~m}$ & 9 \\
\hline 2 & Boeing 747-400 & $70,67 \mathrm{~m}$ & $6,5 \mathrm{~m}$ & 9 \\
\hline 3 & Boeing 777-200 & $63,7 \mathrm{~m}$ & $6.20 \mathrm{~m}$ & 9 \\
\hline
\end{tabular}

Untuk itu dapat ditetapkan ketentuan kategori PKP-PK, dengan menggunakan ketentuan berupa Peraturan Direktur Jendral Perhubungan Udara No. KP 14. Tahun 2015 atau dengan ICAO Airport Service Manual Part 1 Rescue and Fire Fighting pada Tabel 4 sebagai berikut:

Tabel 4. Airport Category for Rescue and Fire Fighting Sumber: ICAO DOC 9137-AN/898 Part 1

\begin{tabular}{|c|c|c|}
\hline $\begin{array}{c}\text { Airport } \\
\text { Category }\end{array}$ & Aeroplane over-all length & $\begin{array}{c}\text { Maximum } \\
\text { Fuselage width }\end{array}$ \\
\hline 1 & 0 up to but no including $9 \mathrm{~m}$ & $2 \mathrm{~m}$ \\
\hline 2 & $9 \mathrm{~m}$ up to but no including $12 \mathrm{~m}$ & $2 \mathrm{~m}$ \\
\hline 3 & $12 \mathrm{~m}$ up to but no including $18 \mathrm{~m}$ & $3 \mathrm{~m}$ \\
\hline 4 & $18 \mathrm{~m}$ up to but no including $24 \mathrm{~m}$ & $4 \mathrm{~m}$ \\
\hline 5 & $24 \mathrm{~m}$ up to but no including $28 \mathrm{~m}$ & $4 \mathrm{~m}$ \\
\hline 6 & $28 \mathrm{~m}$ up to but no including $39 \mathrm{~m}$ & $5 \mathrm{~m}$ \\
\hline 7 & $39 \mathrm{~m}$ up to but no including $49 \mathrm{~m}$ & $5 \mathrm{~m}$ \\
\hline 8 & $49 \mathrm{~m}$ up to but no including $61 \mathrm{~m}$ & $7 \mathrm{~m}$ \\
\hline 9 & $61 \mathrm{~m}$ up to but no including $76 \mathrm{~m}$ & $7 \mathrm{~m}$ \\
\hline 10 & $76 \mathrm{~m}$ up to but no including $90 \mathrm{~m}$ & $8 \mathrm{~m}$ \\
\hline
\end{tabular}

Jika mengacu dari Peraturan Direktur Jendral Perhubungan No. KP 14. Tahun 2015 atau ICAO Airport Service Manual Part 1 Rescue and Fire Fighting, dilihat dari pesawat besar yang mampu mendarat di Bandar Udara Internasional Adi Soemarmo Surakarta. Maka bisa ditetapkan bahwa Fire Fighting di bandara tersebut adalah Fire Fighting Category 9. Tetapi diketahui bahwa Airport Rescue Fire Fighting (ARFF) Bandar Udara Internasional Adi Soemarmo Surakarta adalah kategori 8 yang sudah disertifikasi oleh Direktur Jenderal Perhubungan Udara. Alasan kenapa Bandar Udara Internasional Adi Soemarmo Surakarta dapat melayani B777 yaitu karena pesawat tersebut hanya beroperasi saat penerbangan musim haji atau di musim Ramadhan. Sementara pergerakan pesawat terbanyak per bulan, dengan contoh pergerakan bulan Oktober 2020 pada Tabel 5 
Tabel 5. Pergerakan Pesawat Pada Bulan Oktober 2020

\begin{tabular}{|l|l|c|c|}
\hline No & \multicolumn{1}{|c|}{ Aircraft Type } & Category & Pergerakan per bulan \\
\hline 1 & Boeing 737-900ER & 7 & 101 \\
\hline 2 & Airbus 737-8U3 & 7 & 58 \\
\hline 3 & Airbus 320-214 & 7 & 46 \\
\hline 4 & Boeing 737-800 & 7 & 29 \\
\hline 5 & Boeing 737-500 & 7 & 23 \\
\hline 6 & McDonnell Douglas MD-83 & 7 & 5 \\
\hline
\end{tabular}

Jika dilihat dari Peraturan Direktur Jenderal Perhubungan Udara No. KP 14. Tahun 2015 bahwa dalam menentukan kategori bisa ditentukan dari jumlah pergerakan pesawat udara terbesar yang menggunakan Bandar udara kurang dari 700 (tujuh ratus) pergerakan tersibuk dalam 3 (tiga) bulan berturut-turut (delapan pergerakan per hari), maka penentuan kategori PKP-PK dapat kurang 1 (satu) tingkat dari kategori pesawat udara terbesar. Untuk itu, maka dapat ditentukan PKP-PK Bandar Udara Internasional Adi Soemarmo adalah kategori 8. Tetapi jika dimana saat musim haji terdapat pesawat Wide Body seperti B777-200, B747-400, dan Airbus 330-300 yang mana pesawat tersebut adalah kategori 9, maka penangulangan dari PKPPK itu sendiri dengan cara penambahan personel di shift kerja per hari dan membuka Pos Kesiapsiagaan Pengawasan Umroh Haji guna melayani jika terjadi accident saat musim haji. Untuk Kendaraan Utama tidak perlu adanya penambahan karena 1 unit Foam Tender Type I dan 2 unit Foam Tender Type II dari kemampuannya dapat menangani pesawat terbesar yang dilayani seperti Airbus 330-300, Boeing 747-400, dan Boeing 777-200 yang merupakan pesawat kategori 9.

\section{Kesimpulan}

Tingkat kesiapan dan level minimum kategori Airport Rescue \& Fire Fighting sudah memenuhi standar peraturan yang dikeluarkan Departemen Perhubungan Direktur Jendral Perhubungan Udara Nomor KP.14 tahun 2015. Hal ini bisa ditunjukkan pada Tabel 4.13 Perhitungan Jumlah Minimum Personel yaitu berjumlah 45 personel, dimana personel Airport Rescue \& Fire Fighting (ARFF) Bandar Udara Internasional Adi Soemarmo Surakarta saat ini berjumlah 66 (Senior 16, Junior 0, Basic 50, Non lisensi 0) yang terdapat dilampiran Evaluasi Sertifikasi Pelayanan PKP-PK Kategori 8. Tetapi jika dilihat dari perlengkapan sesuai dengan kesimpulan point 1, untuk kesiapan masih belum memenuhi standar karena terdapat beberapa kekurangan peralatan yang dibutuhkan sesuai dengan peraturan yang dikeluarkan Departemen Perhubungan Direktur Jenderal Perhubungan Udara Nomor KP.14 tahun 2015.Upaya peningkatan Airport Rescue \& Fire Fighting Bandar Udara Internasional Adi Soemarmo Surakarta yaitu dengan melakukan pengadaan peralatan untuk melengkapi batas minimum yang dibutuhkan, peremajaan alat yang sudah tidak berfungsi atau peralatan yang perlu diperbaharui, dan jumlah personel yang sudah ada melebihi jumlah kapasitas tetapi kemampuan kualifikasi masing-masing personel kurang sehingga perlu adanya penambahan training dan pelatihan personel PKP-PK. Aspek lain yang mempengaruhi tingkat kesiapan Airport Rescue \& Fire Fighting Bandar Udara Internasional Adi Soemarmo Surakarta bisa dilihat dari hasil uji Response Time pada rata-rata pencapaian waktu response time dalam 10 bulan terakhir di tahun 2020 saat ini sebesar 119.45 detik, dan rata-rata prosentase waktu pencapaian target response time dalam 10 bulan terakhir di tahun 2020 sebesar 133.64\%. 


\section{Daftar Pustaka}

[1] Direktur Jenderal Perhubungan Udara. 2015. Standar Teknis Dan Operasi Peraturan Keselamatan Penerbangan Sipil Bagian 139 (Manual Of Standard Casr Part 139) Volume IV Pelayanan Pertolongan Kecelakaan Penerbangan Dan Pemadam Kebakaran (PKP-PK). Jakarta: Peraturan Direktur Jenderal Perhubungan Udara.

[2] Andry Kurnianto. 2015. Kajian Kondisi Command Car. Yogyakarta: Perpustakaan STTA.

[3] Budiyanto. 2008. Upaya Peningkatan Kesiapan Tanggap Darurat Unit PKP-PK Sebagai Tidakan Keselamatan Penerbangan Di Area Bandara Sultan Mahmud Badaruddin II Palembang Sumatra Selatan. Yogyakarta: Perpustakaan STTA.

[4] Irfandi Hidayat. 2014. Perencanaan Fire Fighting Station Untuk Mendukung Operasional Pelayanan New Yogyakarta International Airport. Yogyakarta: Perpustakaan STTA. 